\title{
EXPERIMENTAL INVESTIGATION OF POSSIBLE USE OF HDPE AS THERMAL STORAGE MATERIAL IN THERMAL STORAGE TYPE SOLAR COOKERS
}

\author{
Kavendra A. Thakare ${ }^{1}$, Honeykumar G. Vishwakarma ${ }^{2}$, A. G. Bhave ${ }^{3}$

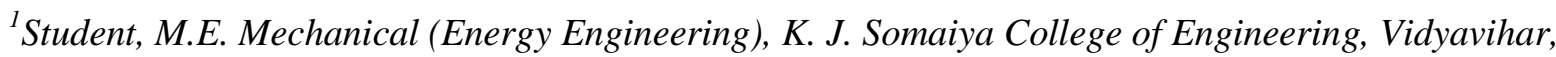 \\ Mumbai-400077, India. Email-ID: kaven.thakare@gmail.com. \\ ${ }^{2}$ Research Intern, Renewable Energy Lab, K. J. Somaiya College of Engineering, Vidyavihar, \\ Mumbai-400077, India. Email-ID: honeykumar.v@gmail.com. \\ ${ }^{3}$ Professor, Department ofMechanical engineering, K. J. Somaiya College of Engineering, Vidyavihar, \\ Mumbai-400077, India. Email-ID:agbhave@gmail.com.
}

\begin{abstract}
Many Phase Change Materials (PCMs) have been investigated by researchers. They reported limitations of PCMs for use in the thermal storage systems, some of them are: high volumetric change in the PCM while undergoing phase change and low thermal conductivity of the PCMs. Literature survey shows that High Density Polyethylene (HDPE) has relevant thermal properties and can be used as PCM. To investigate the possible use of HDPE in the thermal storage type solar cookers. The simple thermal storage device cum cooking device was designed with two stainless steel utensils easily available in the market. Use of HDPE as the PCM in the thermal storage will eliminate the problem of volumetric change as it has low volume change property during phase transition. To eliminate problem of low thermal conductivity rectangular brass fins were used in the design. Bottom of smaller stainless steel vessel (cooking cavity) was brazed with rectangular brass fins in radial manner with roughly equal angular spacing. HDPE was filled in the void space between cooking cavity with fins and outer stainless steel vessel. The device was then tested for heating, cooling and cooking. The results obtained and conclusions drawn from the experimentation are enlisted in this paper.
\end{abstract}

KeyWords: High Density Polyethylene (HDPE), thermal conductivity, latent heat, thermal storage, solar cooker.

\section{INTRODUCTION}

Polyethylene is a widely used plastic material. It has major share in the plastic market. Due to its corrosion resistant property and durability, it has wide range of applications such as house hold items, packaging, insulation, net ropes, pipes and conduits. It is also used in medical applications as a material to make artificial joints [1].

Polyethylene is a thermoplastic therefore can be reprocessed various times in the temperature range of $150^{\circ} \mathrm{C}-250^{\circ} \mathrm{C}$ [2] hence widely used in moulding applications. It is easily and abundantly available in low cost.

Polyethylene is categorized into two major categories on the account of density as follows:

a) Low density polyethylene (LDPE);

b) High density polyethylene (HDPE).

Sometimes polyethylene with intermediate density is called as medium density polyethylene (MDPE). Different polyethylenes have different processing temperature according to their type. DSC characteristics of polyethylene with different densities [3] are as shown in the Fig-1 and 2.

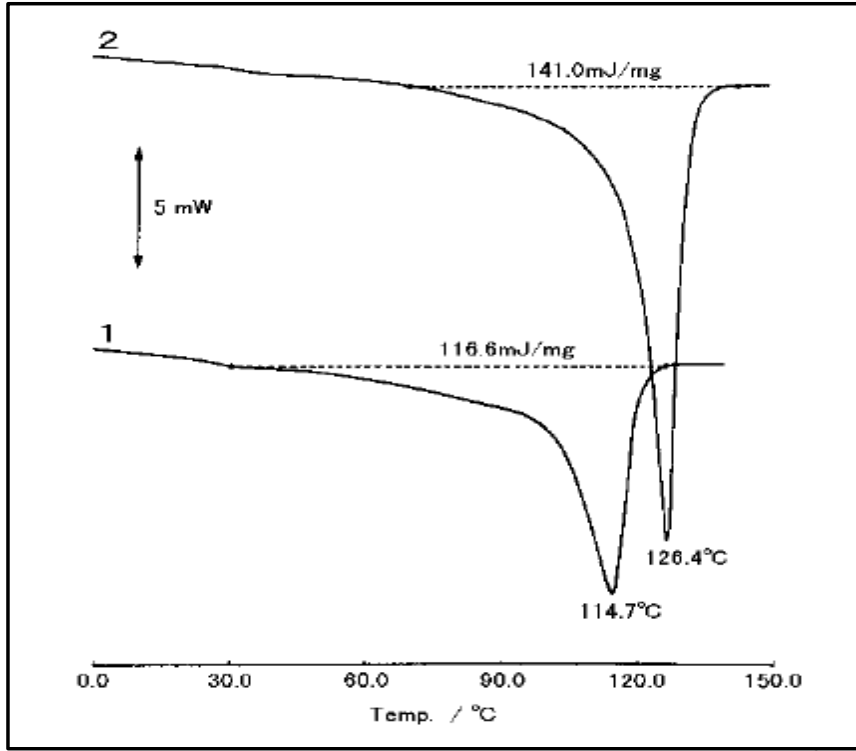

Fig-1: DSC curves of LDPE with density 1) $0.922 \mathrm{~g} / \mathrm{cm}^{3}$ and 2) $0.934 \mathrm{~g} / \mathrm{cm}^{3}$. 


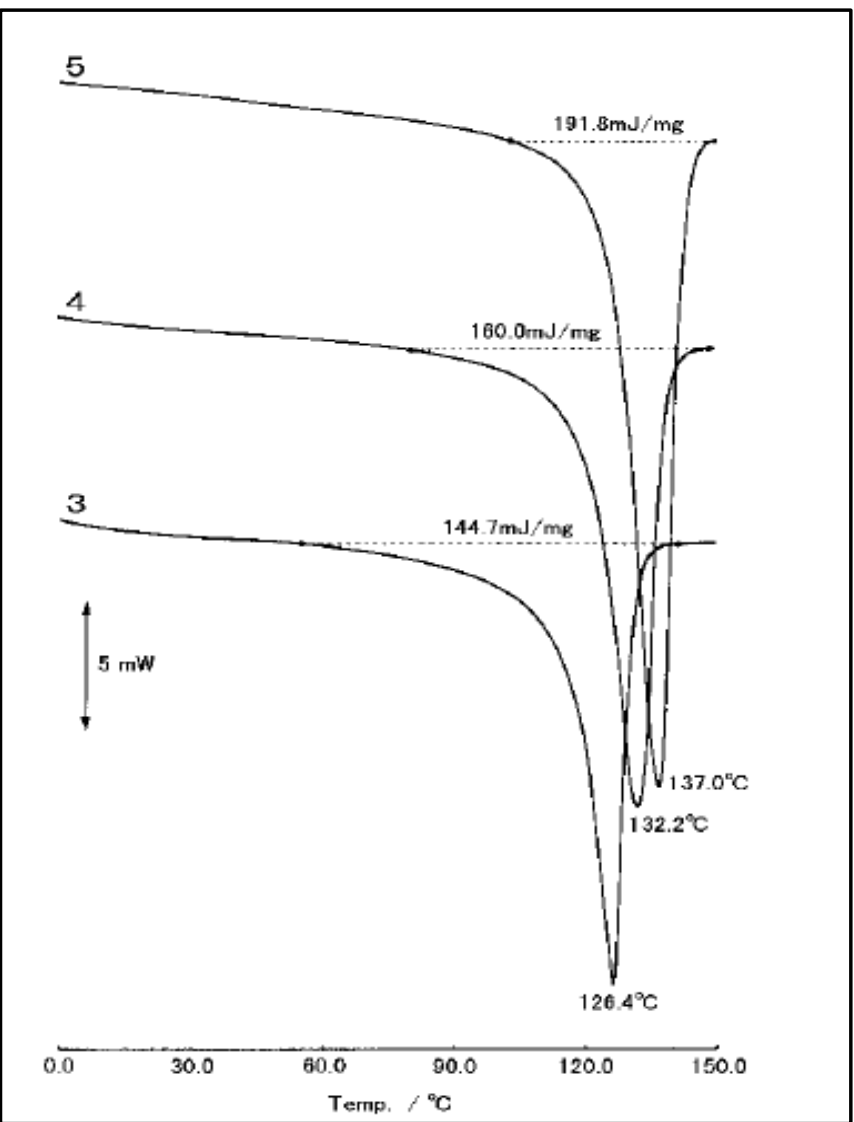

Fig-2:DSC curve for MDPE and HDPE with density

3) $\left.0.935 \mathrm{~g} / \mathrm{cm}^{3} ; 4\right) 0.944 \mathrm{~g} / \mathrm{cm}^{3}$ and 5$) 0.958 \mathrm{~g} / \mathrm{cm}^{3}$.

These characteristics show that polyethylene however loses its properties at temperature above $110^{\circ} \mathrm{C}$ and become soft also flow at higher temperature thus making it unsuitable for high temperature applications. For high temperature applications polyethylene is crosslinked by various methods which improves its thermal properties [3].

The softening of polyethylene in the range of $110^{\circ} \mathrm{C}$ to $140^{\circ} \mathrm{C}$ may seem unsuitable for its various applications but it makes polyethylene suitable for latent type thermal storage material in that temperature range as it absorbs some amount of heat during this phase transition period.

The latent type thermal storage materials are also known as the Phase Change Materials (PCM) as they undergo phase change during storage of thermal energy. PCMs have various applications such as solar thermal storage, in building heating and cooling applications, in preservation of food materials, in space applications and many more. Number of PCMs are available with wide range of Phase transition temperatures. Out of those PCMs having Phase transition temperature around $110^{\circ} \mathrm{C}$ with appropriate latent heat of phase transition can be preferred to use in solar thermal storage in solar cookers for the evening cooking or off sunshine hours cooking [4].

Polyethylene has its phase transition temperature in the range of $110^{\circ} \mathrm{C}-140^{\circ} \mathrm{C}$ which varies with the variation in the density and have sufficient amount of latent heat of fusion thus we decided to investigate its use as thermal storage material in the solar cooker either box type or concentrating type.

\subsection{Properties of HDPE}

DSC curve for melting and crystallization of HDPE [5] are shown in following Fig-3.

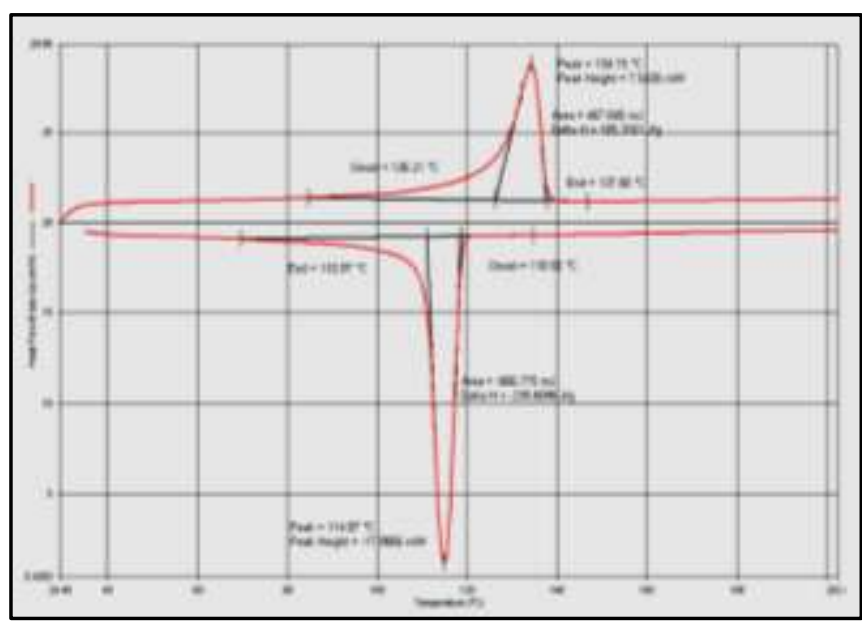

Fig-3: DSC curve for melting and crystallization of HDPE.

From the DSC curve it can be observed that melting temperature of HDPE is around $134^{\circ} \mathrm{C}$ while the crystallization temperature is noted to be $115^{\circ} \mathrm{C}$.

Fig-4 shows the comparison of DSC curves of LDPE and HDPE [5].

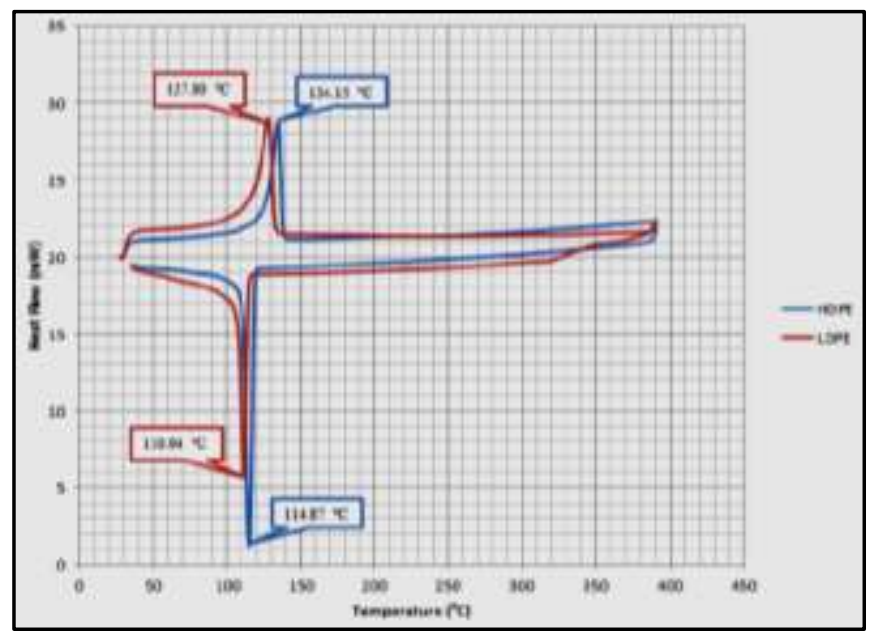

Fig-4: DSC curves for LDPE and HDPE.

Thermophysical properties of HDPE are given in the Table 1.

Table-1: Thermophysical properties of HDPE.

\begin{tabular}{|c|c|}
\hline \multicolumn{2}{|c|}{ High Density Polyethylene (HDPE) [3][5][6]. } \\
\hline Density & $940 \mathrm{~kg} / \mathrm{m}^{3}$. \\
\hline Melting Point & $130.8^{\circ} \mathrm{C}$. \\
\hline $\begin{array}{c}\text { Temperature of } \\
\text { crystallization }\end{array}$ & $111.9{ }^{\circ} \mathrm{C}$. \\
\hline Latent heat of fusion & $178.6 \mathrm{~kJ} / \mathrm{kg}$. \\
\hline Thermal conductivity & $0.44 \mathrm{~W} / \mathrm{m} .{ }^{\circ} \mathrm{C}$. at ${ }^{\circ} \mathrm{C}$. \\
\hline Specific heat (solid) & $1.9 \mathrm{~kJ} / \mathrm{kg} .{ }^{\circ} \mathrm{C}$. \\
\hline Crystallinity & $60 \%$ \\
\hline
\end{tabular}




\subsection{Solar Cookers with thermal storage}

Solar cookers are generally classified as the box type, panel type and concentrating type. But this classification does not give the idea about storage type solar cookers. The Solar cookers can also be broadly categorized as solar cookers (i) with thermal storage and (ii) without thermal storage as discussed by Muthusivagami et al [7].

Many researchers have developed the solar cookers with the thermal storage facility. The thermal storage improves the performance and reliability of the solar cookers by making off-sunshine hours cooking possible. Various PCMs have been used by the various developers. These PCMs have various limitations, but volumetric expansion and poor heat transfer characteristics [4] are the limitations associated with the design of containment. Because of these problems, the design of containment of the PCM and design of thermal storage becomes complicated. The possible solutions to the aforementioned problems are the shape stabilization of PCMs and heat transfer enhancement to and from PCMs. Since HDPE has comparatively low volumetric expansion on heating, it is being used for making of shape stabilized PCMs [1][8]. The problem of low thermal conductivity can be overcome by the use of any heat transfer enhancement technique in the containment design.

\section{Literature Review}

In 1984 Abe et al [8] from Japan found HDPE as suitable PCM in the Latent heat type thermal storage around $120^{\circ} \mathrm{C}$. Later they used form stable HDPE, presently known as cross linked HDPE, as thermal storage material in the direct contact heat exchanger with ethylene glycol and silicone oil as heat transfer fluid. They reported problem of deformation of HDPE even though it was form stabilized.

In the 1996-97 Nandwani et al [9] investigated the use of HDPE as thermal storage material in the box type solar cooker in Germany. They successfully obtained the HDPE slab temperatures around $132^{\circ} \mathrm{C}$ and found performance of the solar cooker with HDPE slab better than solar cooker without HDPE slab.

Fig -5 shows the images of the box type solar cooker used in the experimentation.

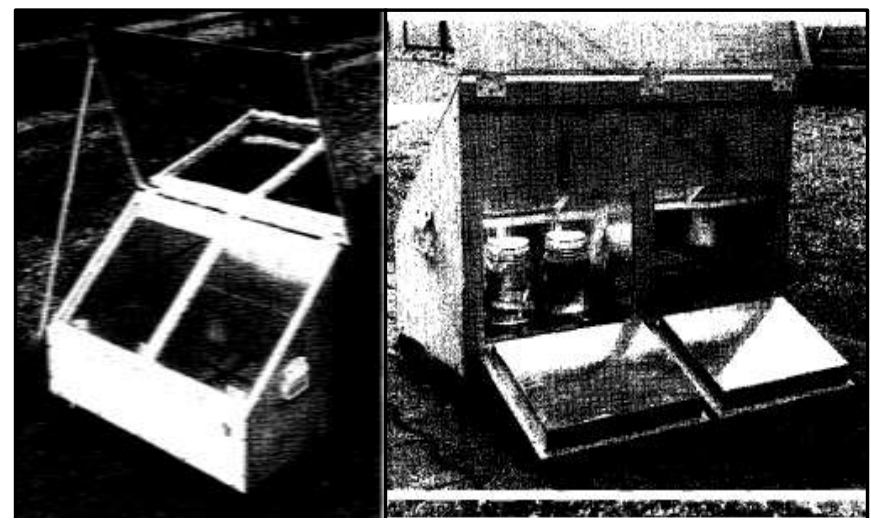

Fig -5: Box type solar cooker used by Nandwani et al [9].

In many cases the PCMs have to be encapsulated to increase its lifespan and prevent direct contact with heat transfer fluid. HDPE is used as the base materail for encapsulation in case of paraffin waxes and 1:1 eutectic mixture of Ammonium alum and ammonium nitrate [11]. The blends made from HDPE and parafin wax can also be used as PCM materials [6]. HDPE has its use in the making of the composite and Shape stabilised PCMs[8][10-13].

HDPE itself can also be used as PCM in the solar thermal storages with operating range $110^{\circ} \mathrm{C}-140^{\circ} \mathrm{C}$. The study by Nandwani et al. shows that HDPE can be used as box type solar cookers as thermal storage material, also HDPE can be used as storage medium in the concentrating type solar cookers where temperature around $150^{\circ} \mathrm{C}$ are easily achievable.

\section{Thermal Storage cum cooking Device}

From the properties of HDPE and literature review, it is clear that HDPE can be used as PCM in the thermal storage systems. So we decided to investigate the possible use of HDPE in the storage type solar cookers. Though HDPE has promising phase transition temperature $\left(130.8^{\circ} \mathrm{C}\right)$ and latent heat storage capacity $(178.6 \mathrm{~kJ} / \mathrm{kg})$, it has low thermal conductivity $\left(0.44 \mathrm{~W} / \mathrm{m} .{ }^{\circ} \mathrm{C}\right)$ too. It becomes viscous when undergoes phase transition thus the conduction will be the prominent mode of heat transfer. Hence to make the use of HDPE in thermal storage one needs to enhance heat transfer to and from the HDPE. For that purpose fins were used in the present experimentation on the thermal storage with HDPE.

To investigate the use of HDPE in the solar cooker with thermal storage facility, we designed the thermal storage device on a smaller scale with two stainless steel utensils, one having bigger diameter and height than the second. Rectangular brass fins were brazed to the bottom of the smaller stainless steel vessel (i.e. cooking cavity) in radial manner with roughly equal angular spacing. Fins enhance the heat transfer to and from the HDPE in heat collection period and heat retrieval period respectively.

The Fig- 6 shows the constructional details of the device.

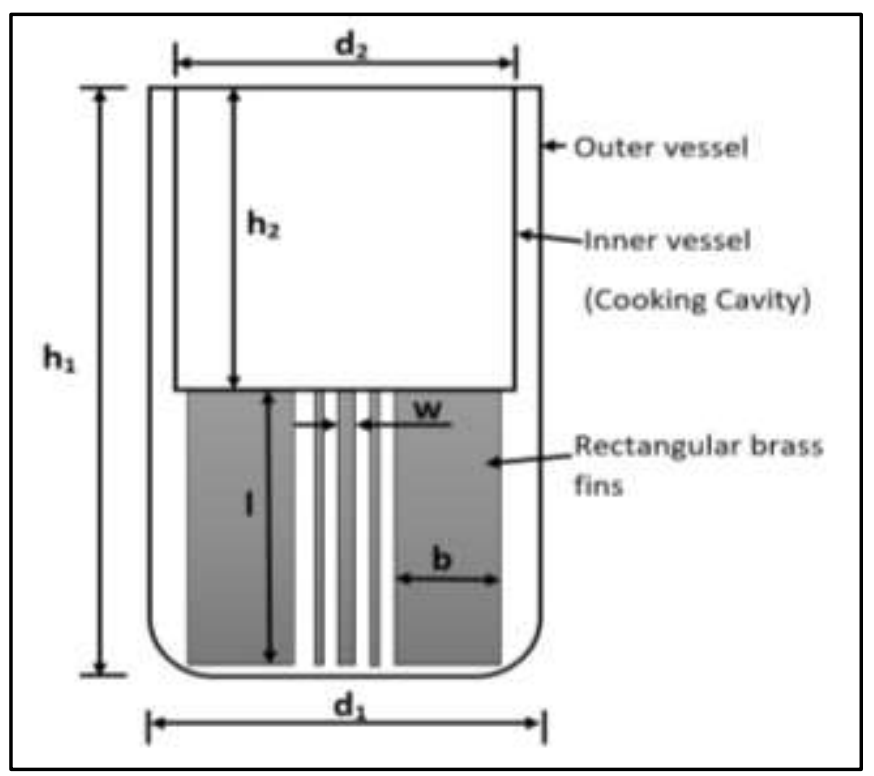




\begin{tabular}{|c|c|c|c|}
\hline $\mathrm{d}_{1}$ & $6.5 \mathrm{~cm}$ & $\mathrm{~d}_{2}$ & $6 \mathrm{~cm}$ \\
\hline $\mathrm{h}_{1}$ & $9 \mathrm{~cm}$ & $\mathrm{~h}_{2}$ & $4.5 \mathrm{~cm}$ \\
\hline $\mathrm{l}$ & $4.5 \mathrm{~cm}$ & $\mathrm{~b}$ & $2 \mathrm{~cm}$ \\
\hline $\mathrm{w}$ & $0.5 \mathrm{~mm}$ & $\mathrm{n}$ & 8 fins \\
\hline
\end{tabular}

Fig -6: Constructional details of thermal storage device.

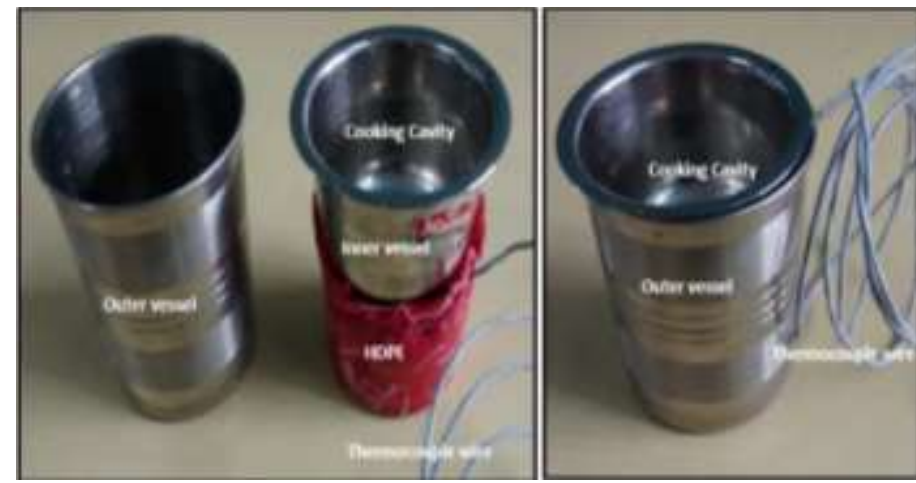

Fig -7: Images of Assembly of thermal storage device.

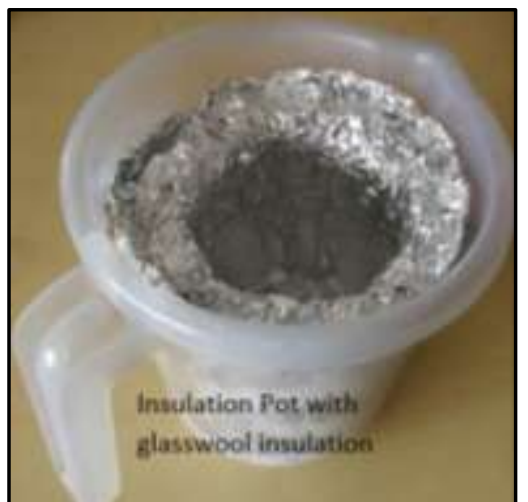

Fig -8: Insulation pot with glasswool insulation.

\section{Experimentation and Results}

$115 \mathrm{gm}$ of HDPE was used in the device to store heat and a hot air oven was used to simulate solar heating of the device. As the properties of available HDPE were unknown, for calculations, properties were assumed to be same as mentioned in the Table-1. The HDPE was heated to the melting point in the bigger utensil (shown as outer vessel in the Fig-7) then the smaller vessel was pressed to fit against the molten HDPE. A thermocouple was inserted into the HDPE such that it can give the HDPE temperature from the center of the device. The final assembly is as shown in Fig7.

\subsection{Heating and Cooling Test}

The heating (Melting of HDPE) and cooling (Crystallization of HDPE) tests were carried out on the device. Heating test comprised of preheating of the hot air oven till the set temperature and then heating of device in the oven till the HDPE temperature reaches around $150^{\circ} \mathrm{C}$. After that the device was taken out from the oven and kept inside the insulation pot and allowed to cool with controlled heat loss to the surrounding.

The observation tables of the heating and cooling test of the device are illustrated in the Table- 2 and 3 with the corresponding graphs i.e. Graph 1 and 2 respectively.
The sensible and latent heating phases of the HDPE can be observed from the Graph 1. While in Graph 2 the low slope of the temperature curve between $125^{\circ} \mathrm{C}$ to $110^{\circ} \mathrm{C}$ indicates the release of latent heat from the HDPE.

Table-2: Temperature readings of Heating Test 1.

\begin{tabular}{|c|c|c|c|}
\hline $\begin{array}{c}\text { Time } \\
(\mathbf{m i n})\end{array}$ & $\begin{array}{c}\mathbf{T}_{\text {HDPE }} \\
\left({ }^{\circ} \mathbf{C}\right)\end{array}$ & $\begin{array}{c}\mathbf{T}_{\text {oven }} \\
\left({ }^{\circ} \mathbf{C}\right)\end{array}$ & $\begin{array}{c}\mathbf{T}_{\text {set }} \\
\left({ }^{\circ} \mathbf{C}\right)\end{array}$ \\
\hline 0 & 32 & 160 & 160 \\
\hline 10 & 76 & 160 & 160 \\
\hline 20 & 106 & 160 & 160 \\
\hline 30 & 120 & 160 & 160 \\
\hline 35 & 124 & 160 & 160 \\
\hline 40 & 126 & 160 & 160 \\
\hline 45 & 129 & 160 & 160 \\
\hline 50 & 131 & 160 & 160 \\
\hline 55 & 134 & 160 & 160 \\
\hline 65 & 143 & 160 & 160 \\
\hline 70 & 148 & 160 & 160 \\
\hline 75 & 152 & 160 & 160 \\
\hline 77 & 154 & 160 & 160 \\
\hline
\end{tabular}

Table-3: Temperature readings of Cooling Test.

\begin{tabular}{|c|c|}
\hline $\begin{array}{l}\text { Time } \\
\text { (min) }\end{array}$ & $\begin{array}{c}\mathbf{T}_{\text {HDPE }} \\
\left({ }^{\circ} \mathbf{C}\right)\end{array}$ \\
\hline 0 & 154 \\
\hline 2 & 149 \\
\hline 4 & 143 \\
\hline 6 & 136 \\
\hline 8 & 130 \\
\hline 10 & 125 \\
\hline 15 & 123 \\
\hline 18 & 123 \\
\hline 20 & 122 \\
\hline 22 & 121 \\
\hline 24 & 120 \\
\hline 26 & 118 \\
\hline 28 & 117 \\
\hline 30 & 116 \\
\hline 32 & 114 \\
\hline 34 & 112 \\
\hline 36 & 110 \\
\hline 38 & 107 \\
\hline 40 & 105 \\
\hline 42 & 103 \\
\hline 44 & 100 \\
\hline 46 & 98 \\
\hline
\end{tabular}




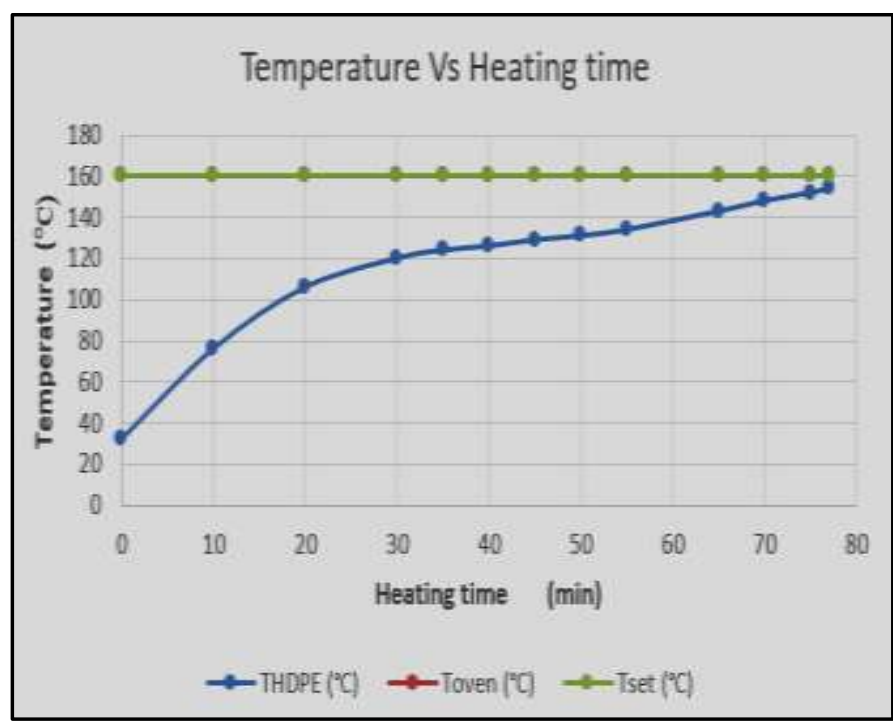

Graph 1: Temperature Vs Heating time 1.

\section{THDPE Vs Cooling time}

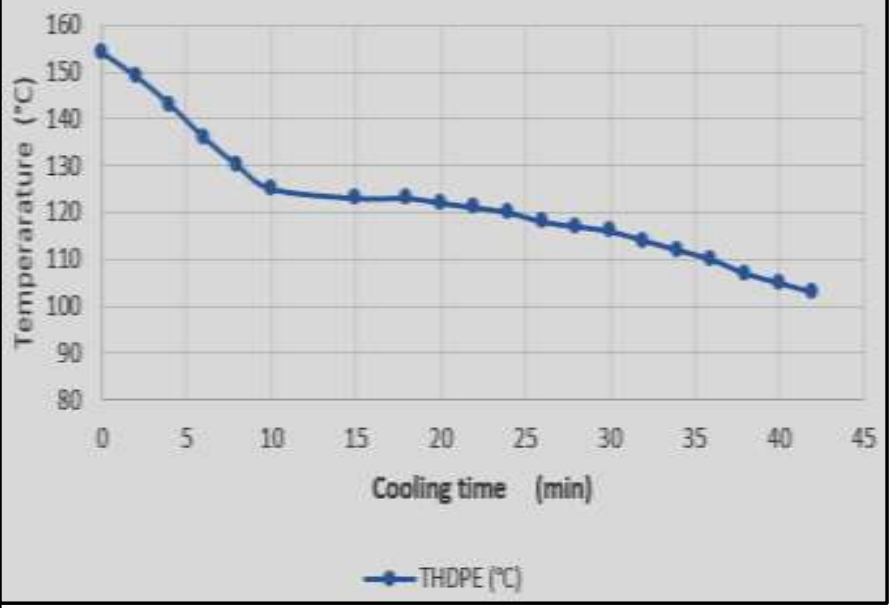

Graph 2: Temperature Vs Cooling time.

\subsection{Cooking Test}

For cooking test the device was heated in the oven in similar manner to that of the heating and cooling test except that the preheating of oven was not done. HDPE was heated till its temperature crosses the melting point. After that device was taken out from the oven and kept in the insulation pot to minimize the heat loss to the surrounding. $15 \mathrm{gm}$ of rice with $30 \mathrm{ml}$ of water was put in the cooking cavity provided on the device. The cooking cavity was covered with a lid to avoid heat losses to the surrounding while cooking and then the food was allowed to cook. The HDPE temperature during cooking test was recorded at regular intervals. The cooking time for given amount of food, was observed to be around 25 minutes. Afterwards the weight of cooked rice was recorded for further calculations. The observation table for heating and cooking test carried out on the device are presented in the Table- 4 and 5 with the corresponding graphs i.e. Graph 3 and 4 respectively. From the Graph 3, the sensible and latent heating phase of the HDPE can be observed. While the low slope of the temperature curve between $115^{\circ} \mathrm{C}$ to $100^{\circ} \mathrm{C}$ during cooking indicated the release of latent heat from the HDPE.

Fig-9 shows the image of cooked rice in the cooking cavity with the device kept inside the insulation pot.

Table-4: Temperature readings of Heating Test 2.

\begin{tabular}{|c|c|c|c|}
\hline $\begin{array}{c}\text { Time } \\
(\mathbf{m i n})\end{array}$ & $\begin{array}{c}\mathbf{T}_{\text {HDPE }} \\
\left({ }^{\circ} \mathbf{C}\right)\end{array}$ & $\begin{array}{c}\mathbf{T}_{\text {oven }} \\
\left({ }^{\circ} \mathbf{C}\right)\end{array}$ & $\begin{array}{c}\mathbf{T}_{\text {set }} \\
\left({ }^{\circ} \mathbf{C}\right)\end{array}$ \\
\hline 0 & 30 & 30.9 & 150 \\
\hline 10 & 71 & 107 & 150 \\
\hline 25 & 120 & 149 & 150 \\
\hline 40 & 134 & 150 & 150 \\
\hline 55 & 141 & 150 & 150 \\
\hline
\end{tabular}

Table-5: Temperature readings of Cooking Test.

\begin{tabular}{|c|c|}
\hline $\begin{array}{c}\text { Time } \\
(\mathbf{m i n})\end{array}$ & $\begin{array}{c}\mathbf{T}_{\text {HDPE }} \\
\left({ }^{\circ} \mathbf{C}\right)\end{array}$ \\
\hline 0 & 135 \\
\hline 2 & 122 \\
\hline 4 & 116 \\
\hline 6 & 112 \\
\hline 8 & 110 \\
\hline 10 & 108 \\
\hline 12 & 107 \\
\hline 14 & 106 \\
\hline 16 & 105 \\
\hline 18 & 104 \\
\hline 20 & 103 \\
\hline 22 & 102 \\
\hline 24 & 101 \\
\hline 26 & 99 \\
\hline
\end{tabular}




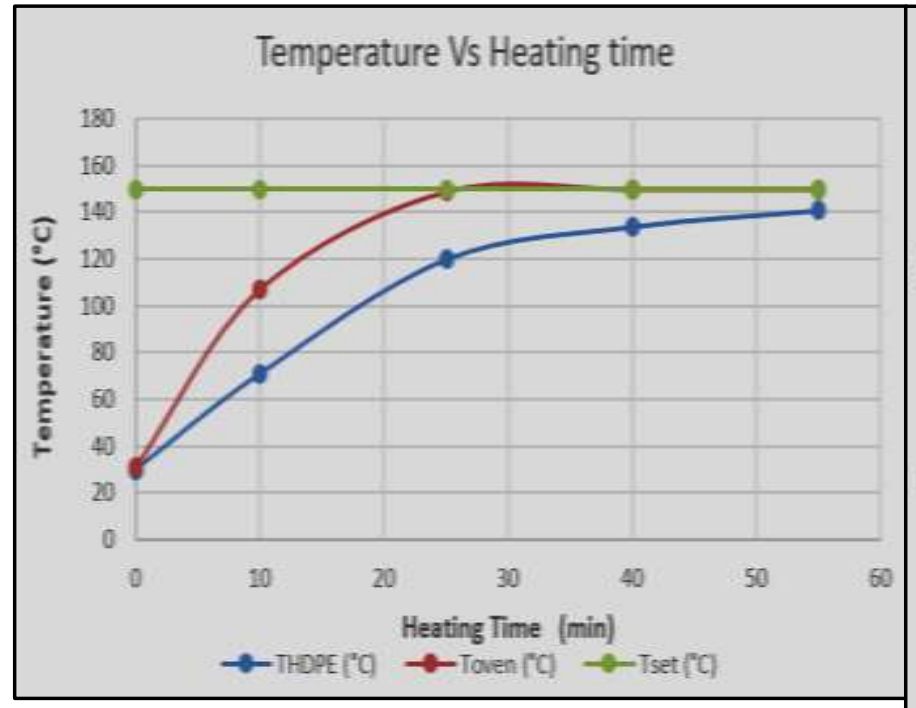

Graph 3: Temperature Vs Heating time 2.

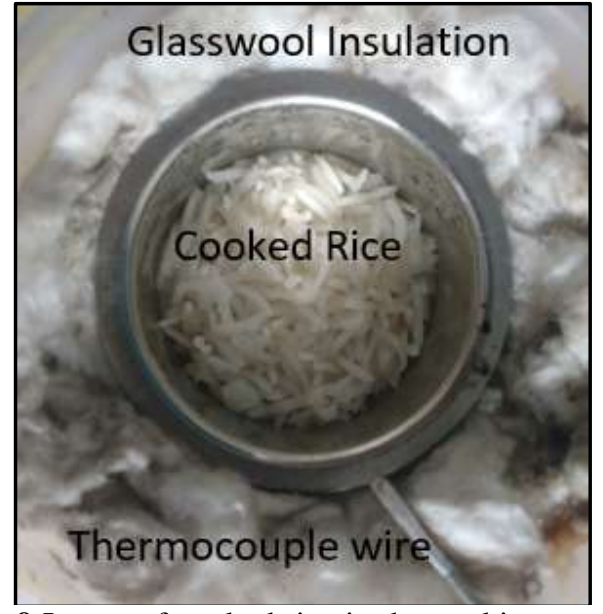

Fig-9:Image of cooked rice in the cooking cavity.

Few more heating and cooking tests were carried out on the device and similar results were obtained.

\section{Calculations}

Table-6 enlists the data used for calculations.

Table-6: Data used for calculations.

\begin{tabular}{|c|c|c|c|}
\hline$m_{s c}$ & $20 \mathrm{gm}$ & $C_{p s c}$ & $500 \mathrm{~J} / \mathrm{kg} .{ }^{\circ} \mathrm{C}$ \\
\hline$m_{\text {fin }}$ & $50 \mathrm{gm}$ & $C_{p f i n}$ & $380 \mathrm{~J} / \mathrm{kg} .{ }^{\circ} \mathrm{C}$ \\
\hline$m_{H s}$ & $115 \mathrm{gm}$ & $C_{p H s}=C_{p H l}$ & $1.9 \mathrm{~kJ} / \mathrm{kg} .{ }^{\circ} \mathrm{C}$ \\
\hline$H_{L_{H}}$ & $180 \mathrm{~kJ} / \mathrm{kg}$ & $T_{f}$ & $141^{\circ} \mathrm{C}$ \\
\hline$T_{m}$ & $131^{\circ} \mathrm{C}$ & $T_{a}$ & $30^{\circ} \mathrm{C}$ \\
\hline$m_{r}$ & $15 \mathrm{gm}$ & $C_{p r}$ & $1.716 \mathrm{~kJ} / \mathrm{kg} .{ }^{\circ} \mathrm{C}$ \\
\hline$m_{w}$ & $30 \mathrm{gm}$ & $C_{p w}$ & $4.187 \mathrm{~kJ} / \mathrm{kg} .{ }^{\circ} \mathrm{C}$ \\
\hline$m_{w e}$ & $7 \mathrm{gm}$ & $H_{L_{w}}$ & $2256 \mathrm{~kJ} / \mathrm{kg}$ \\
\hline
\end{tabular}

\section{THDPEV Vs Cooking time}

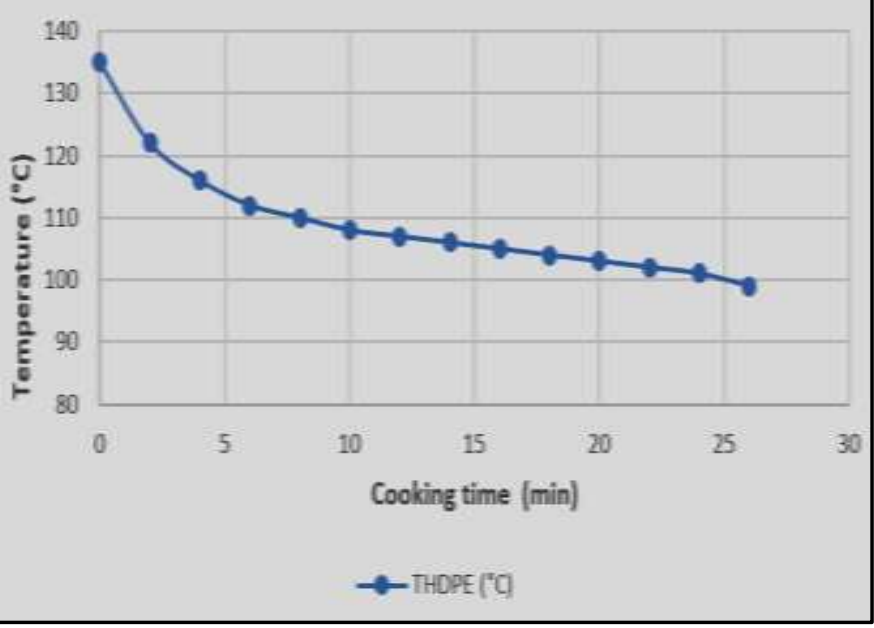

Graph 4: Temperature Vs Cooking time.

\subsection{Energy balance calculations:}

Total thermal Energy stored throughout the heating test neglecting energy stored in outer vessel is given as:

Total Thermal Energy Stored

$$
\begin{aligned}
& =m_{s c} C_{p s c}\left[T_{f}-T_{a}\right]_{s c} \\
& +m_{\text {fin }} C_{p f i n}\left[T_{f}-T_{a}\right]_{f i n} \\
& +m_{H s} C_{p H s}\left[T_{m}-T_{a}\right]_{H s}+m_{H s} H_{L_{H}} \\
& +m_{H l} C_{p H l}\left[T_{f}-T_{m}\right]_{H l} \ldots \ldots(1) \\
\therefore Q_{\text {stored }} & =48.173 \mathrm{~kJ} .
\end{aligned}
$$

Similarly thermal energy stored above $100^{\circ} \mathrm{C}$ in the HDPE and cooking cavity which is useful for boiling type of cooking is given as:

Total Thermal Energy Stored above $100^{\circ} \mathrm{C}$

$$
\begin{aligned}
& \quad=m_{s c} C_{p s c}\left[T_{f}-100\right]_{s c} \\
& +m_{\text {fin }} C_{p f i n}\left[T_{f}-100\right]_{f i n} \\
& +m_{H s} C_{p H s}\left[T_{m}-100\right]_{H s}+m_{H s} H_{L_{H}} \\
& \quad+m_{H l} C_{p H l}\left[T_{f}-T_{m}\right]_{H l} \ldots \ldots(2) \\
& \therefore Q_{\text {stored }}>100^{\circ} \mathrm{C}=30.848 \mathrm{~kJ} .
\end{aligned}
$$

Energy required to cook $15 \mathrm{~g}$ of rice with $30 \mathrm{ml}$ of water is given as: (mass of cooked rice $=43 \mathrm{gm})$

Energy required to cook $15 \mathrm{~g}$ rice with $30 \mathrm{ml}$ of water

$$
\begin{aligned}
& =m_{r} C_{p r}\left[100-T_{a}\right]_{r} \\
& +m_{w} C_{p w}\left[100-T_{a}\right]_{w} \\
& +m_{w e} H_{L_{w}} \ldots \ldots(3) \\
\therefore & Q_{\text {cooking }}=26.387 \mathrm{~kJ} .
\end{aligned}
$$




\subsection{Efficiency Calculations:}

Cooking efficiency with respect to total thermal energy stored is given as:

$$
\begin{aligned}
& \eta_{\text {stored }}=\frac{Q_{\text {cooking }}}{Q_{\text {stored }}} \\
& \therefore \eta_{\text {stored }}=\frac{26.387}{48.173}=0.5478=55.78 \% .
\end{aligned}
$$

Cooking efficiency with respect to thermal energy stored above $100^{\circ} \mathrm{C}$ is given as:

$$
\begin{aligned}
& \eta_{\text {stored }>100^{\circ} \mathrm{C}}=\frac{Q_{\text {cooking }}}{Q_{\text {stored }>100^{\circ} \mathrm{C}}} \\
& \therefore \eta_{\text {stored }>100^{\circ} \mathrm{C}}=\frac{26.387}{30.848}=0.8554=85.54 \% . . .
\end{aligned}
$$

\section{CONCLUSIONS}

Following conclusions are drawn from the experimentation carried on the HDPE.

1. Graphs for heating and cooling test show the similar temperature trends to the ideal heating and cooling curves in case of Latent heat stored and released.

2. Temperature trends in the graphs show that the latent heat was stored and released near respective melting and crystallization temperatures of HDPE.

3. Energy balance and efficiency calculations show that the device has good thermal characteristics.

4. The higher values of efficiencies may be due to assumed properties of HDPE but seem to be attractive.

5. The concept of thermal storage device was proved.

6. The overall results show that the HDPE can be used as PCM in storage type solar cookers.

\section{Nomenclature}

$\begin{array}{ll}\text { PCM } & \text { Phase Change Material } \\ \text { HDPE } & \text { High Density Polyethylene } \\ \text { LDPE } & \text { Low Density Polyethylene } \\ \text { DSC } & \text { Differential Scanning Calorimetry } \\ m & \text { Mass }(\mathrm{kg}) \\ C_{p} & \text { Specific heat }\left(\mathrm{kJ} / \mathrm{kg} .{ }^{\circ} \mathrm{C}\right) \\ T & \text { Temperature }\left({ }^{\circ} \mathrm{C}\right) \\ H_{L} & \text { Latent heat of Phase transition }(\mathrm{kJ} / \mathrm{kg})\end{array}$

$Q$

$H$

$n$

Suffix

sc

fin

Hs

$\mathrm{Hl}$

$r$

w

We

F

$a$

$m$

stored

stored $>100^{\circ} \mathrm{C}$

cooking

oven

set

Quantity of heat (kJ)

Efficiency

Number of fins

Stainless steel cooking cavity

Brass fins

HDPE solid

HDPE liquid

Rice

Water

Water evaporated

Final

Ambient

Melting

Total stored

Stored above $100^{\circ} \mathrm{C}$

For cooking

Oven

Set temperature of oven

\section{REFERENCES}

[1].http://bonesmart.org/knee/knee-replacement-implantmaterials/ (cited on Dec 2015)

[2].S.Tamboli et al, Crosslinked polyethylene, Indian Journal of Chemical Technology, Vol-11 (Nov-2004),pp 853-864.

[3].Application brief on "DSC Measurement of Polyethylene", TA no.26 Feb 1986, Hitachi High-Tech Science Corporation.

[4]. Atul Sharma et al, Review on thermal energy storage with phase change materials and applications, Renewable and Sustainable Energy Reviews, vol-13 (2009), pp 318345.

[5].Abdullah Al Ashraf, Thermal Analysis of Polymers by DSC Technique, 2015, Centre for Advanced studies, Qatar University.

[6].M.E. Sotomayor et al., Thermal and mechanical characterization of injection moulded high density polyethylene/paraffin wax blends as phase change materials, Renewable Energy, vol- 68 (2014), pp 140-145.

[7]. R.M. Muthusivagami et al., Solar cookers with and without thermal storage - A review, Renewable and Sustainable Energy Reviews, vol-14 (2010), pp 691-701.

[8].Y. Abe et al, Charge and Discharge Characteristics of a Direct Contact Latent Thermal Energy Storage Unit Using Form-Stable High-Density Polyethylene, Journal of Solar Energy Engineering, vol-106 (Nov 1984), pp 465-474.

[9]. S Nandwani et al, Experimental Study of Multipurpose Solar Hot Box at Freiburg, Germany, Renewable Energy vol-12 (1997), pp 1-12. 
[10].B. Zalba et al, Review on thermal energy storage with phase change: materials, heat transfer analysis and applications, Applied Thermal Engineering, vol-23 (2003),pp 251-283.

[11].M. M. Farid, et.al., A review on phase change energy storage: materials and applications. Energy Conversion and Management 45 (2004), pp.1597-1615.

[12].H. Mehling\&L.F.Cabeza, Heat and Cold Storage with PCM (2008), Chapter-2, Page no. 11-52, Springer.

[13].Kavendra Thakare and A.G. Bhave, Review on latent heat storage and problems associated with phase change materials, International Journal of Research in Engineering and Technology, vol-4 (2015), pp 176-182.

\section{BIOGRAPHIES}

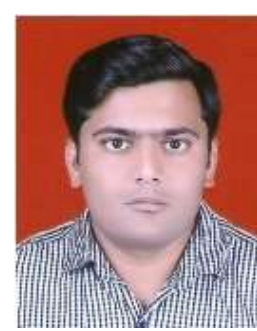

Kavendra A. Thakare received the B. Tech. degree in Marine Engineering from Maharashtra Academy of Naval Education and Training, Pune in 2010. $\mathrm{He}$ is now pursuing M.E. in Energy Engineering from K. J. Somaiya College of Engineering, Mumbai University.

Email-ID: kaven.thakare@gmail.com

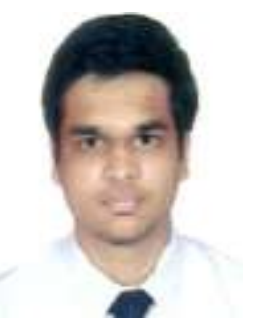

\section{Honeykumar G. Vishwakarma}

completed his Bachelor of Engineering in Mechanical Engineering from K. J. Somaiya College of Engineering, Mumbai. Currently doing internship in Renewable Energy Lab, K.J.Somaiya College of Engineering.

\section{Email-ID: honeykumar.v@gmail.com}

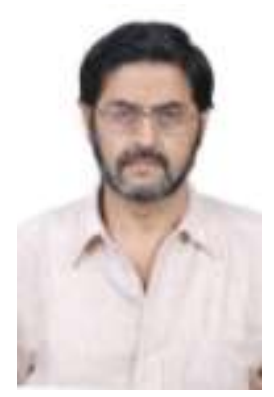

Dr. A.G. Bhave received the degree of Docteur - Ingenieur in Thermique Industrielle, in the area of solar thermal energy, from Universite Paris XII in 1985. He has worked in the renewable energy area since, and is working as a professor in the Mechanical Engineering Department of K. J. Somaiya College of Engineering, Mumbai since 2009.

Email-ID: agbhave@gmail.com 